\title{
Expenditure-based segmentation and visitor profiling at The Quays in Salford, UK
}

\author{
RUTH CRAggS
}

School of H ospitality M anagement and Tourism, Faculty of Tourism and Food, D ublin

Institute of Technology, Cathal Brugha Street, Dublin 1, Ireland.

E-mail: ruth.craggs@dit.ie.

\section{Peter Schofield}

M aM S Research Institute, Salford Business School, M axwell Building, U niversity of

Salford, G reater M anchester M 5 4W T, UK. E-mail: p.schofiedd@salford.ac.uk.

There is a substantial body of literature relating to tourism's economic impact at the macro level, but less is known about tourist expenditure at a micro scale. This paper reports findings from a survey of day-visitor expenditure by category at The Quays in Salford, UK. Expenditure is influenced strongly by the visitor's age, frequency of visitation and visit motivation. Heavy, medium and light expenditure segments and associated profiles are identified. 'H eavy spenders' are more likely to be female, in a family group and have shopping as the main motivation for the visit. The implications of the findings are discussed.

Keywords: visitor expenditure; market segmentation; visitor profiling; Salford Quays

Tourism has long been viewed as a tool for economic development due to its ability to generate substantial economic benefits to host regions and communities. This is evident principally in former industrial regions and their waterfront areas where the forces of globalization have diminished manufacturing industries in favour of progression in the service sector. Policy for regenerating these areas has been concerned with a range of measures affecting the economy, but tourism has been accorded an increasingly important role. However, while a considerable amount is known about the general value of tourism at the macro level (inter alia Wanhill, 1994; Vaughan et al, 2000) and much research has been undertaken by consultants for clients at both destination and sub-destination levels, there is a lack of published research relating to visitor expenditure at the micro level (Parlett et al, 1995; D ownward and Lumsdon, 2003). The academic studies which have examined visitor expenditure at the micro level (inter alia Gyte and Phelps, 1989; Godbey and 
Graefe, 1991; Spotts and Mahoney, 1991; Oppermann, 1997; Legoherel, 1998; $\mathrm{McH}$ one and Rungeling, 1999; Agarnal and Yochum, 2000; Downward and Lumsdon, 2000, 2003; Mok and Iverson, 2000; Jang et al, 2004; Lehto et al, 2004; Petrick, 2005; Suh and McAvoy, 2005) are wide ranging with respect to the types of product market under investigation, and there is a gap in the literature regarding visitor expenditure at regenerated waterfront destinations. This study therefore takes up the metaphorical gauntlet thrown down by Sheldon (1990) to examine spending patterns at the micro level, with a specific focus on The Quays in Salford, M anchester's regenerated dockland area.

$G$ reater Manchester's tourism industry has burgeoned in recent years, to the extent that it has eclipsed the area's traditional industries. As part of this development, The Quays area of Salford has been positioned as its flagship tourism product using a formula based on a broad mix of commercial, residential and tourism elements. As yet, its economic impacts have escaped quantification. Consequently, research questions relating to visitor expenditure, the measurement of economic benefits and the opportunity cost of redevelopment with respect to spin-off for the local community have not been addressed. Given the local nature of the study and the size of The Quays' economy, macroeconomic techniques such as input-output analysis and the use of economic multipliers were unsuitable because, as has been found elsewhere, appropriate data for multiplier calculations were not available (Walpole and Goodwin, 2000). The Quays' visitor, employee and resident expenditure was therefore measured in an attempt to quantify local economic impacts. The paper reports the findings from a questionnaire survey of day-visitor expenditure at The Quays in Salford as part of a larger study of the destination concerned with user perceptions, behaviour and experience. It focuses on expenditure patterns of heavy, medium and light expenditure segments by local category/tourism product component and examines the significance of a range of socio-economic and behavioural variables.

\section{Literature review}

Previous research has found that a wide range of variables has influenced visitor expenditure. For example, Gyte and Phelps's (1989) study found higher expenditure among repeat visitors than first-timers, while most subsequent studies found a negative relationship between expenditure and frequency of attendance or visitation. Godbey and Graefe (1991) assessed the impact of the frequency of attendance at football games at Pennsylvania State U niversity on visitor expenditure and found a strong negative relationship between per games expenditure and repeat visitation; tourists attending one game spent three times as much on items as those attending all or most of the games. Similarly, Oppermann's (1997) study of travel expenditure of repeat and first-time visitors to $\mathrm{N}$ ew Zealand found repeat visitors had lower travel expenditure per day compared to first-time visitors. Lehto et al (2004) found that prior experience of a destination resulted in reduced expenditure because of visitors' increased knowledge of a place, and Jang et al (2004) also found the frequency of visitation to be an influencing factor in explaining visitor expenditure. Firsttime visitors spent more than repeat visitors because the latter were better 
acquainted with the destination and therefore more able to budget their travel expenses; visitors with companions al so spent more than those who were visiting al one.

$\mathrm{N}$ ot surprisingly, visitor income has been found to be a significant variable in determining consumer expenditure. Davies and Morgan (1996) analysed the UK Family Expenditure Survey to investigate the effect of income on hotel and holiday expenditure. Their research confirmed expenditure to be income elastic. Elasticity varied considerably between different income groups, being high for low income groups and low but elastic for high income groups. Agarnal and Yochum's (2000) study of overnight visitors to Virginia Beach, USA, al so found expenditure to be associated positively with income, as was length of stay, party size, number of children and age of the group leader. D ownward and Lumsdon's (2003) study of visitor expenditure in Herefordshire, England, also found income to be a significant influence on expenditure, as was group size. By comparison, Downward and Lumsdon's (2000) study of the determinants of visitor expenditure at Cheddar, England, found that rather than the size of groups, group composition together with duration of stay were influential variables.

Suh and M cAvoy (2005) examined preferences and expenditures of European, $\mathrm{N}$ orth A merican and J apanese travellers to South K orea and found that, regardless of origin, business travellers spent more than pleasure travellers in total trip expenditure. $\mathrm{MCH}$ one and Rungeling (1999) also found significant differences in expenditure based on the purpose of the trip. Casual leisure visitors and those who attended a cultural exhibition in Orlando were differentiated significantly on the basis of expenditure patterns and demographic characteristics; cultural exhibition attendees had higher incomes, were older and had higher expenditure on food and shopping compared to casual leisure visitors.

Various studies have segmented the tourist market into different expenditure groups and established the characteristics of each group (Pizam and Reichel, 1979; W oodside et al, 1987; Spotts and Mahoney, 1991; Legoherel, 1998; Mok and Iverson, 2000; Petrick, 2005). M ok and Iverson (2000) used travel expenditure as a segmentation variable in their study of Tai wanese travellers to Guam. They divided their sample into three categories of spenders: light, medium and heavy, based on their total expenditure in Guam. No significant differences between the expenditure segments were found on the basis of income, marital status, gender and occupation. H owever, heavy spenders were distinguishable from other segments by length of stay, party size, trip purpose and travel mode, and were significantly younger (95\% were under 50 years old). Using a oneway analysis of variance (ANOVA), they identified significant differences between the three segments in all local expenditure categories except for transportation and entertainment. All three expenditure segments spent significantly more on shopping than on any other expenditure category, and heavy spenders had greater expenditure in all categories.

In a study of Michigan's Peninsula, Spotts and M ahoney (1991) found heavy spenders were distinguishable from other segments on the basis of their larger party sizes, longer breaks, greater involvement with recreation and higher propensity to use information disseminated by the region's travel industry. U sing cluster analysis, Petrick (2005) segmented cruise ship passengers into 
three categories based on their price sensitivity ('Iow sensitives', 'moderate sensitives' and 'high sensitives'). Passengers who were less price sensitive had higher household incomes and spent more money per day on their cruise than passengers who were more price sensitive. He also found 'moderate sensitives' and 'high sensitives' to be more satisfied overall.

\section{Methodology}

A mixed-method approach was employed for the primary research. This consisted of preliminary qualitative research, including interviews and content analysis of promotional material, to underpin the design of the instrument for the questionnaire survey.

\section{Instrumentation}

The questionnaire was designed to measure visitor perceptions of The Quays, their behaviour and expenditure both overall and by local category/tourism product component, together with relevant sociodemographic data. The main section of the questionnaire consisted of 30 attitude statements about The Quays presented to day-trip visitors in the form of a 'performance-only' construct, on balanced 5-point Likert-type scales anchored at 'D isagree Strongly' (1) to 'Agree Strongly' (5), with each intervening option labelled and numbered appropriately. Subjects were asked to indicate their level of agreement with the statements. Visitors' overall satisfaction and intention both to recommend The Quays and to return to the destination were also measured on 5-point scales.

\section{Sampling design}

After an initial pilot study in July 2004 which resulted in minor amendments, an on-site self-administered questionnaire was distributed around The Quays' attractions, bars, restaurants and distributional outlets between August and December 2004. Additionally, an intercept survey was conducted throughout A ugust and September 2004. Given that The Quays has numerous entry and exit points, expenditure data were not collected when visitors were arriving or leaving the destination. Instead, respondents were asked to recall expenditure al ready made and provide estimates of expected expenditure for the remainder of their trip. While the unreliability of subject recall and estimation of expenditure has been highlighted by previous research (Pearce, 1988; Faulkner and Raybould, 1995), due to the short duration of the visit, it was predicted that visitors would recall expenditure accurately and, al beit to a lesser extent, be able to estimate their expenditure on the rest of their visit to The Quays. Alternative methods of measuring visitor expenditure, such as using visitor expenditure diaries, were considered to be impractical (Frechtling, 1974; Breen et al, 2001).

K rejcie and Morgan's (1970) formula, as recommended by Jennings (2001), was used to calculate a viable sample for the survey:

$$
s=\chi^{2} N P(1-P) \div d^{2}(N-1)+\chi^{2 P}(1-P)
$$


where:

$\mathrm{s}=$ required sample size;

$\chi^{2}=$ the table value of chi-square for one degree of freedom at the desired confidence level (3.841);

$\mathrm{N}=$ the population size;

$P=$ the population proportion (assumed to be 0.5 , since this would provide the maximum sample size);

$d=$ the degree of accuracy expressed as a proportion (0.05).

It was estimated that approximately two million people visited The Quays in 2003 (Salford City Council, 2004) and no further breakdown of this figure was available on any aspect of the visitor profile. A minimum sample of 387 subjects was therefore required. DeVaus (2002) and Veal (2006) also suggest a sample size of 387 for a population of two million, with a $5 \%$ margin of error. A total of 392 useable questionnaires were obtained from a convenience sample. A nonprobability sample was taken because of the constraints imposed by the destination's numerous entry and exit points (Finn et al, 2000), the dispersal of the population around the destination's attractions and amenities and the restricted opportunities for interception. H owever, the sample was considered to be representative of typical visitors to The Quays because the target population was sampled at nine different locations throughout the destination in an attempt to capture any variability.

\section{D ata analysis}

The data were analysed using SPSS Version 12.0. A range of tests was employed to examine the influence of variables on visitor expenditure. An expenditurebased segmentation technique was employed which divided respondents into four expenditure segments based on their total actual expenditure in The Quays area (after Mok and I verson, 2000). Chi-square, t-tests and one-way AN OVA were performed to test for significant associations and differences between expenditure segments and categories on the basis of a range of sociodemographic and visit-specific variables. Heavy, medium and light expenditure profiles were then developed.

\section{Results and discussion}

Visitors were asked to state their actual expenditure at The Quays in each category on the day of the survey up to the time at which they were intercepted and asked to complete a questionnaire. Given the relatively short time that subjects had been at The Quays prior to taking part in the survey, the data are considered to be an accurate representation of actual visitor expenditure. Because subjects were surveyed at various stages in their day trip to The Q uays, they were also asked to estimate their expenditure in each category over the rest of the day. While this was considered to be a less accurate measure of visitor expenditure, particularly where subjects had no particular plan, it nevertheless provided both a more comprehensive picture than would otherwise have been the case and a means of comparing actual with estimated data. It was interesting to note that independent sample t-tests and one-way ANOVA to test for 
Table 1. Actual visitor expenditure by local category.

\begin{tabular}{|c|c|c|c|c|c|c|c|c|}
\hline $\begin{array}{l}\text { Expenditure } \\
\text { category of } \\
\end{array}$ & $\begin{array}{l}\text { Number } \\
\text { of subjects } \\
\text { 'spending' } \\
\text { in each } \\
\text { category }\end{array}$ & $\begin{array}{l}\% \text { Spend } \\
\text { in each } \\
\text { category }\end{array}$ & $\begin{array}{l}\text { Maximum } \\
\text { spend in } \\
\text { each } \\
\text { category } \\
\text { (f) }\end{array}$ & $\begin{array}{l}\text { Total } \\
\text { spend in } \\
\text { each } \\
\text { category } \\
\text { (f) }\end{array}$ & $\begin{array}{l}\text { Mean } \\
\text { spend } \\
\text { (f) }\end{array}$ & SD & $\begin{array}{l}\text { Mean } \\
\text { spend per } \\
\text { spending } \\
\text { visitor* } \\
\text { (E) }\end{array}$ & $\begin{array}{l}\text { Median } \\
\text { spend } \\
\text { (f) }\end{array}$ \\
\hline Shopping & & & 200.0 & $4,037.2$ & 10.3 & 27.6 & 40.4 & 25.0 \\
\hline $\begin{array}{l}\text { Restaurants } \\
\text { Coffee shops/ }\end{array}$ & & & & 1 & 3.2 & 7.3 & & 8.0 \\
\hline $\begin{array}{l}\text { cafes } \\
\text { Admission/ }\end{array}$ & 173 & 44.1 & 20.0 & $1,052.3$ & 2.7 & 3.9 & 6.3 & 5.0 \\
\hline & 44 & & 40.0 & 500.4 & 1.3 & 5.0 & 11.6 & 7.0 \\
\hline Public transport & 82 & 20.9 & & & 1. & 5.0 & 5.0 & 4.6 \\
\hline Bars & 17 & 4.3 & 40.0 & 184.3 & 0.5 & 2.9 & 10.9 & 8.0 \\
\hline Parking & 26 & 6.6 & 5.0 & 86.0 & 0.2 & 0.9 & 3.3 & 3.0 \\
\hline
\end{tabular}

N ote: *Excluding non-spending visitors in each category.

Table 2. Estimated visitor expenditure by local category.

\begin{tabular}{|c|c|c|c|c|c|c|c|c|}
\hline $\begin{array}{l}\text { Expenditure } \\
\text { category }\end{array}$ & $\begin{array}{l}\text { Number } \\
\text { of subjects } \\
\text { 'spending' } \\
\text { in each } \\
\text { category }\end{array}$ & $\begin{array}{l}\% \text { Spend } \\
\text { in each } \\
\text { category }\end{array}$ & $\begin{array}{l}\text { Maximum } \\
\text { spend in } \\
\text { each } \\
\text { category } \\
\text { (f) }\end{array}$ & $\begin{array}{l}\text { Total } \\
\text { spend in } \\
\text { each } \\
\text { category } \\
\text { (E) }\end{array}$ & $\begin{array}{l}\text { Mean } \\
\text { spend } \\
\text { (f) }\end{array}$ & SD & $\begin{array}{l}\text { Mean } \\
\text { spend per } \\
\text { spending } \\
\text { visitor* } \\
\text { (f) }\end{array}$ & $\begin{array}{l}\text { Median } \\
\text { Spend } \\
\text { (f) }\end{array}$ \\
\hline Shopping & 63 & 16.1 & 500.0 & $3,368.2$ & 8.6 & 37.9 & 53.5 & 28.0 \\
\hline $\begin{array}{l}\text { Restaurants } \\
\text { Coffee shops/ }\end{array}$ & & & & & & & & 8.0 \\
\hline & 30 & 7.7 & 15.0 & 217.1 & 0.6 & 2.2 & 7.2 & 6.0 \\
\hline & 15 & 3.8 & 30.0 & 157.0 & 0.4 & 2.5 & 10.5 & 9.0 \\
\hline Public transport & 21 & & & & & & & 3.0 \\
\hline Bars & 13 & 3. & 54. & & 0. & & 15.1 & 10.0 \\
\hline Parking & 9 & 2.3 & 5.0 & 36.0 & 0.1 & 0.6 & 4.0 & 4.0 \\
\hline
\end{tabular}

$\mathrm{N}$ ote: *Excluding non-spending visitors in each category.

differences between subjects' expenditure by a range of variables including gender, age, education level, socio-economic class and purpose of trip showed significant differences between variables for the actual expenditure data, but not for the estimated data. This suggested that subjects were unable to predict their expenditure by category accurately over the remainder of their time at The Quays; the analysis of visitor expenditure therefore focused on actual expenditure data.

An analysis of total actual visitor expenditure by category showed that most visitor expenditure $(£ 4,037.20)$ was on shopping (a primary element of the attraction of The Quays), with $25.8 \%$ of visitors spending in this category (Table 1). Expenditure in restaurants $(£ 1,253.40)$ and cafes $(£ 1,052.30)$ was al so 
notable, with $29.8 \%$ and $44.1 \%$ of visitors spending in these categories, respectively. By comparison, expenditure on entry fees at the other primary attractions ( $f 500.40$ ) and in bars (£184.30) was relatively low, with only $11.2 \%$ and $4.3 \%$ of visitors spending in these categories, respectively. The mean expenditure per spending visitor, that is, where non-spending visitors in each category are excluded, shows a similar pattern, although expenditure on admission/entry fees and in bars is ranked higher, as would be expected from the relatively low numbers spending in these categories. The median actual expenditure data by local category also reflect these figures, while highlighting the deviation from the mean, particularly in terms of shopping.

The figures for esti mated visitor expenditure (over the remainder of their time at The Quays) by category are given in Table 2. The rank order of estimated and actual expenditure by local category is identical, although estimated expenditure in each category is lower than actual expenditure, with the exception of bars, where there is a $6.35 \%$ increase. It is interesting that al though mean estimated expenditure is lower in each category except for bars, where it is equal, the mean estimated spend per spending visitor is higher for five of the seven categories; only estimated admission/entry fee and public transport expenditure are lower than mean actual spend per spending visitor in these categories. By comparison with median actual expenditure, median estimated expenditure in each category is slightly higher, except for restaurants (where it is equal) and public transport (where it is lower). As with the actual expenditure data, a comparison of the mean estimated spend per spending visitor and median estimated expenditure data by category highlights the skew in the estimated shopping expenditure distribution.

Subjects' raw actual expenditure data for the seven categories were aggregated to determine overall expenditure at The Quays during the visit. This was then subdivided into four segments: 'no expenditure', 'light expenditure'

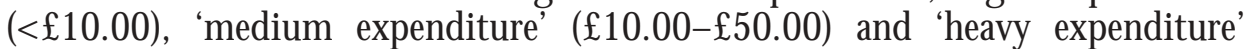
$(>f 50.00)$. The distribution of subjects across the four segments is as follows: $89(22.7 \%)$ in the no expenditure segment, $158(40.3 \%)$ in light expenditure, $100(25.5 \%)$ in medium expenditure and $45(11.5 \%)$ in the heavy expenditure segment. In other words, approximately 1 in 10 visitors are heavy spenders and 1 in 4 are in the medium expenditure segment, whereas 2 in every 5 visitors are light spenders and 1 in 5 incur no expenditure. Overall, the light expenditure segment spent $£ 867.40$ (mean: $£ 5.50$; median: $£ 4.00$ ), the medium expenditure segment spent $f 2,336.50$ (mean: $f 23.40$; median: $f 8.00$ ) and the heavy expenditure segment spent $£ 4,311.10$ (mean: $£ 95.80$; median: $£ 15.00$ ).

The distribution of light, medium and heavy subjects who incurred expenditure in each local category is given in Table 3. Just over half $(53.2 \%)$ of subjects in the light segment incurred expenditure in cafes, with $26.0 \%$ in restaurants and $20.3 \%$ on public transport. By comparison, there is a more even distribution of expenditure across the categories in the medium segment; while expenditure in cafes is comparable (56\%), $43 \%$ of subjects incurred expenditure in restaurants, $42 \%$ on shopping, $35 \%$ on public transport and $25 \%$ on entry to attractions. The pattern is similar in the heavy expenditure segment, with notable peaks in the proportion of subjects spending in the shopping (95.5\%), cafe $(60.0 \%)$ and restaurant $(57.8 \%)$ categories.

$M$ ean and median figures for light, medium and heavy expenditure segments 
Table 3. Heavy, medium and light segment subjects' expenditure in each local category.

\begin{tabular}{|c|c|c|c|c|c|c|}
\hline \multirow[t]{2}{*}{$\begin{array}{l}\text { Expenditure } \\
\text { category }\end{array}$} & \multicolumn{2}{|c|}{$\begin{array}{l}\text { Light expenditure } \\
\text { segment } \\
(n=158)\end{array}$} & \multicolumn{2}{|c|}{$\begin{array}{l}\text { Medium expenditure } \\
\text { segment } \\
(n=100)\end{array}$} & \multicolumn{2}{|c|}{$\begin{array}{l}\text { Heavy expenditure } \\
\text { segment } \\
(n=45)\end{array}$} \\
\hline & $\mathrm{N}$ & $\%$ & $\mathrm{~N}$ & $\%$ & $\mathrm{~N}$ & $\%$ \\
\hline Entry/attractions & 5 & 3.2 & 25 & 25 & 12 & 26.7 \\
\hline Restaurants & 42 & 26.0 & 43 & 43 & 26 & 57.8 \\
\hline Cafes & 84 & 53.2 & 56 & 56 & 27 & 60.0 \\
\hline Bars & 3 & 1.9 & 11 & 11 & 3 & 6.7 \\
\hline Shopping & 15 & 9.5 & 42 & 42 & 43 & 95.6 \\
\hline Car parking & 8 & 5.1 & 16 & 16 & 2 & 4.4 \\
\hline Public transport & 32 & 20.3 & 35 & 35 & 13 & 28.9 \\
\hline
\end{tabular}

$N$ ote: AN OVA results showed significant differences $(p<0.01)$ between the segments in all local expenditure categories.

Table 4. Expenditure in heavy, medium and light segments by local category.

\begin{tabular}{lccc}
\hline Expenditure & Light expenditure & Medium expenditure & Heavy expenditure \\
category & segment & segment & segment \\
& (f) & (f) & (f)
\end{tabular}

Mean Median Mean Median Mean Median

Expenditure on entry/

\begin{tabular}{|c|c|c|c|c|c|c|}
\hline \multirow{2}{*}{\multicolumn{7}{|c|}{$\begin{array}{l}\text { attractions } \\
\text { Expenditure in }\end{array}$}} \\
\hline & & & & & & \\
\hline Expenditure in cafes & 2.6 & 5.0 & 4.6 & 7.5 & 4.0 & 5.0 \\
\hline Expenditure in bars & 0.1 & 8.0 & 1.0 & 5.0 & 1.3 & 20.0 \\
\hline $\begin{array}{l}\text { Expenditure on } \\
\text { shopping } \\
\text { Expenditure on car }\end{array}$ & 0.4 & 3.9 & 7.3 & 15.0 & 72.2 & 57.0 \\
\hline & 0.1 & 3.0 & 0.6 & 4.0 & 0.6 & 3.0 \\
\hline transport & 0.5 & 2.5 & 1.6 & $.00^{3.5}$ & 3.4 & $45^{4.0}$ \\
\hline
\end{tabular}

$N$ ote: AN OVA results showed significant differences $(p<0.01)$ between the segments in all local expenditure categories.

in each local category are given in Table 4. A one-way AN OVA showed that significant differences $(p<0.01)$ were found between the expenditure segments in all local expenditure categories. This supports the findings of Mok and Iverson's (2000) study of Taiwanese travellers to Guam. For the light expenditure segment, mean expenditure is highest in cafes ( $£ 2.60)$ and restaurants (f1.50), with median expenditure at $f 5.00$ in both categories.

As would be expected given the data in Table 3 , there is a more even distribution of expenditure across the categories in the medium and heavy 
expenditure segments. A comparison of medium and light segments' mean expenditure in local categories shows that the medium segment's figures are higher in each case. This is reflected by the median expenditure data, with the exception of expenditure on entry to attractions and in bars. For the medium expenditure segment, the highest expenditure is on shopping (mean: f7.30; median: $f 15.00$ ), restaurants (mean: $f 5.70$; median: $f 10.00$ ) and cafes (mean: £4.60; median: f7.50). The heavy expenditure segment's mean and median expenditure in all local categories is higher than that of the medium segment (with the exception of slightly lower expenditure in cafes and equal expenditure on car parking). This also lends some support to the findings of Mok and Iverson (2000). The outstanding expenditure category for the heavy expenditure segment is shopping (mean: f72.20; median: $f 57.00$ ); expenditure in restaurants (mean: $f 10.10$; median: $f 11.00$ ), on entry/attractions (mean: $f 4.60$; median: $f 12.00$ ) and on public transport (mean: $f 3.40$; median: $f 4.00$ ) are also high compared with the light and medium expenditure segments.

Overall, shopping expenditure is the highest among the categories for both medium and heavy expenditure segments. This also supports the findings of Mok and Iverson (2000), although in their research, shopping was also the highest category for the light expenditure segment. In this case, the latter incur most expenditure in cafes.

\section{Variables influencing total expenditure}

A number of statistical tests were conducted to determine the association between visitor gender, age, socio-economic class, highest level of education attained, visit purpose, frequency of visitation, group size, composition and type, overall satisfaction and perceptions of The Quays' attributes on subjects' expenditure.

The t-test for the influence of gender on total expenditure showed a significant difference between males $(\underline{M}=2.15, S D=0.88)$ and females $(\underline{M}$ $=2.37, \mathrm{SD}=0.99 ; \mathrm{t}(381.22)=2.29, \bar{p}=0.02)$, al though the effect size, using eta squared was small (0.01). Gender was not found to be an influencing variable by either Mok and Iverson (2000) or Jang et al (2004).

A one-way ANOVA was used to test for differences in total expenditure on the basis of age. Significant differences were found between the expenditure segments $[F(3,388)=6.93, p<0.001]$, with an intermediate size effect (eta squared $=0.05$ ). P ost hoc comparisons using the Scheffe test indicated that the mean score for the 55-64 age group $(\mathrm{M}=2.70, \mathrm{SD}=0.94)$ was significantly higher than that for the 25-34 $(\underline{\mathrm{M}}=2.04, \mathrm{SD}=0.86)$ and the $16-24(\mathrm{M}=$ $2.13, \mathrm{SD}=0.86$ ) age groups. By comparison, Mok and Iverson (2000) found heavy spenders were significantly younger. No significant differences were found on the basis of age when expenditure was examined at the individual attraction/ visit component level.

$\mathrm{N}$ o significant differences in total expenditure were found on the basis of socio-economic class. Petrick (2005) found that socio-economic class was a significant influence on expenditure, albeit with respect to international vacations. No significant differences were found on the basis of highest level of education attained, organized tours, educational trips or visiting with 
partners, friends or colleagues. Business/conference attendance was not found to be a significant influence on expenditure at The Quays. By comparison, Suh and McAvoy (2005) found that business travellers spent more in total trip expenditures than pleasure travellers, although the focus of their study was on international business trips to South Korea.

Total expenditure was significantly higher for shoppers $(\underline{M}=2.61, S D=$ 1.06) than for non-shoppers $[\underline{M}=2.09, S D=0.82 ; t(196.52)=4.78, p<0.001$; eta squared $=0.06$ ]. This lends further support to the findings of $M$ ok and Iverson (2004). Total expenditure was significantly higher for leisure visitors $(\underline{M}=2.47, S D=0.94)$ than for subjects who worked on The Q uays $[\mathrm{M}=1.85$, $\mathrm{SD}=0.78 ; \mathrm{t}(390)=6.90, p<0.001$; eta squared $=0.01]$; this may be some function of the time available for expenditure. Total expenditure was also significantly higher for infrequent visitors than for frequent visitors $[F(6,385)$ $=3.75, p=0.001$; eta squared $=0.06$ ]. This supports the findings of Godbey and Graefe (1991), Oppermann (1996, 1997), Jang et al (2004) and Lehto et al (2004). It was also significantly higher for people visiting with family ( $\underline{M}$ $=2.61, \mathrm{SD}=1.05)$ than without $[\mathrm{M}=2.17, \mathrm{SD}=0.88 ; \mathrm{t}(390)=3.38, \mathrm{p}=$ 0.001 ; eta squared $=0.03$ ] and significantly lower for individuals $(\mathrm{M}=2.07$, $\mathrm{SD}=0.77)$ than for people visiting The Quays with others $[\mathrm{M}=2.34, \mathrm{SD}$ $=0.99 ; \mathrm{t}(390)=2.92, p=0.004$; eta squared $=0.02]$. J ang et al $(2004)$ found that travelling with partners, friends and colleagues increased expenditure significantly. W hile many variables have a statistically significant influence on visitor expenditure, it is notable that the proportion of variance in total expenditure explained by visitor age, frequency of visitation and shopping as the main motivation for the visit was significantly higher.

A one-way, between-groups AN OVA was used to test for differences between The Quays' attribute ratings of visitors in the four expenditure segments. There was a statistically significant difference $(p<0.05)$ between the segments on 'an attractive place' $[F(3,388)=3.01, p=0.03]$. Despite reaching statistical significance, the actual difference in the mean ratings between the segments was small; the effect size, calculated using eta squared, was 0.02. Expenditure segment mean ratings were also significantly different on 'usually something new to see' $[F(3,388)=6.93, p<0.001]$, with an intermediate size effect (eta squared $=0.05)$. P ost hoc comparisons using the Scheffe test indicated that the mean score for the medium expenditure segment $(\underline{M}=3.66, S D=1.31)$ was significantly higher than that for the no expenditure segment $(\mathrm{M}=3.08$, SD $=1.12)$, and the mean score for the high expenditure segment $(\underline{M}=3.91$, SD $=1.22$ ) was significantly higher than that for the low expenditure segment ( $\mathrm{M}$ $=3.26, \mathrm{SD}=1.21$ ). A significant difference between expenditure segment mean ratings was also found on 'a place to take the family' $[F(3,388)=3.02, p=$ $0.03]$, although the effect size was small (eta squared $=0.02$ ). P ost hoc comparisons showed that the mean score for the high expenditure segment ( $\mathrm{M}=$ 4.04, SD $=0.85$ ) was significantly higher than that for the low expenditure segment $(\mathrm{M}=3.75, \mathrm{SD}=0.91)$. Expenditure segment mean ratings were al so significantly different on 'good quality shopping' $[F(3,388)=3.85, p=0.01]$, with a relatively small effect size (eta squared $=0.03$ ). Post hoc comparisons showed that the mean score for the high expenditure segment $(\underline{M}=4.02$, SD $=0.92$ ) was significantly higher than that for the low expenditure segment ( $\mathrm{M}$ $=3.44, \mathrm{SD}=1.14$ ). $\mathrm{H}$ igher ratings on attributes (significantly higher in the 
last three cases) were recorded for the higher expenditure segments compared with the lower expenditure segments. No other statistically significant differences between the four expenditure segments on the mean attribute ratings were found.

\section{Variables influencing visitor expenditure by category}

Visitor expenditure by category (admission/entry fees, restaurants, coffee shops/ cafes, bars, shopping, parking and public transport) was analysed to determine the existence and strength of associations with gender, age, socio-economic class, highest level of education attained, visit purpose, frequency of visitation and group size, composition and type. The results of chi-square tests with associated phi and Cramer's V-statistics are given in Table 5.

Theatres, cinemas, museums and shopping are the primary attractions of The Quays. Expenditure on admission/entry to attractions is associated significantly, al beit weakly, with general sightseeing, visitor employment with organizations located on The Quays, visit frequency, visiting either as an individual or with a partner and with age of visitors, in addition to the more obvious 'visiting an attraction' as the main motivation for the visit. Expenditure on shopping has a statistically significant but weak association, with only three variables: shopping as the main motivation for the visit, visitor employment with organizations located on The Quays and visits with family.

Restaurants, cafes and bars are the main secondary features of The Quays' visitor economy. Expenditure in restaurants has a statistically significant but weak association with visitor employment with organizations located on The Quays, organized tours of The Quays and with visitor age and occupation, as well as 'eating and drinking', as would be expected.

Predictably, expenditure in cafes/coffee shops has a significant but weak association with 14 out of the 22 variables tested. In addition to the variables that are associated with expenditure on admission/entry to attractions and in restaurants, expenditure in cafes has a significant but weak association with walking, visiting with friends and colleagues, group size and highest education level attained by visitors. By comparison, expenditure in bars has a significant but weak association with only two variables: visit frequency and visiting with friends.

From the perspective of access to The Quays, expenditure on car parking is associated significantly but weakly with walking, visiting attractions, visitor employment with organizations located on The Quays, visit frequency, visiting with a partner, group size, highest education level attained and gender. Expenditure on public transport has a significant but weak association with attending business meetings and conferences and with group size.

A number of other associations between variables are also of interest. $\mathrm{N}$ ot surprisingly, expenditure on attractions, in restaurants and cafes, on shopping and on car parking is associated significantly with employment in organizations located on The Quays. By contrast, business and conference visits are associated significantly with use of public transport. Individual visits and visits with partners are associated significantly with expenditure on attractions and in cafes. By comparison, family visits are associated significantly with 


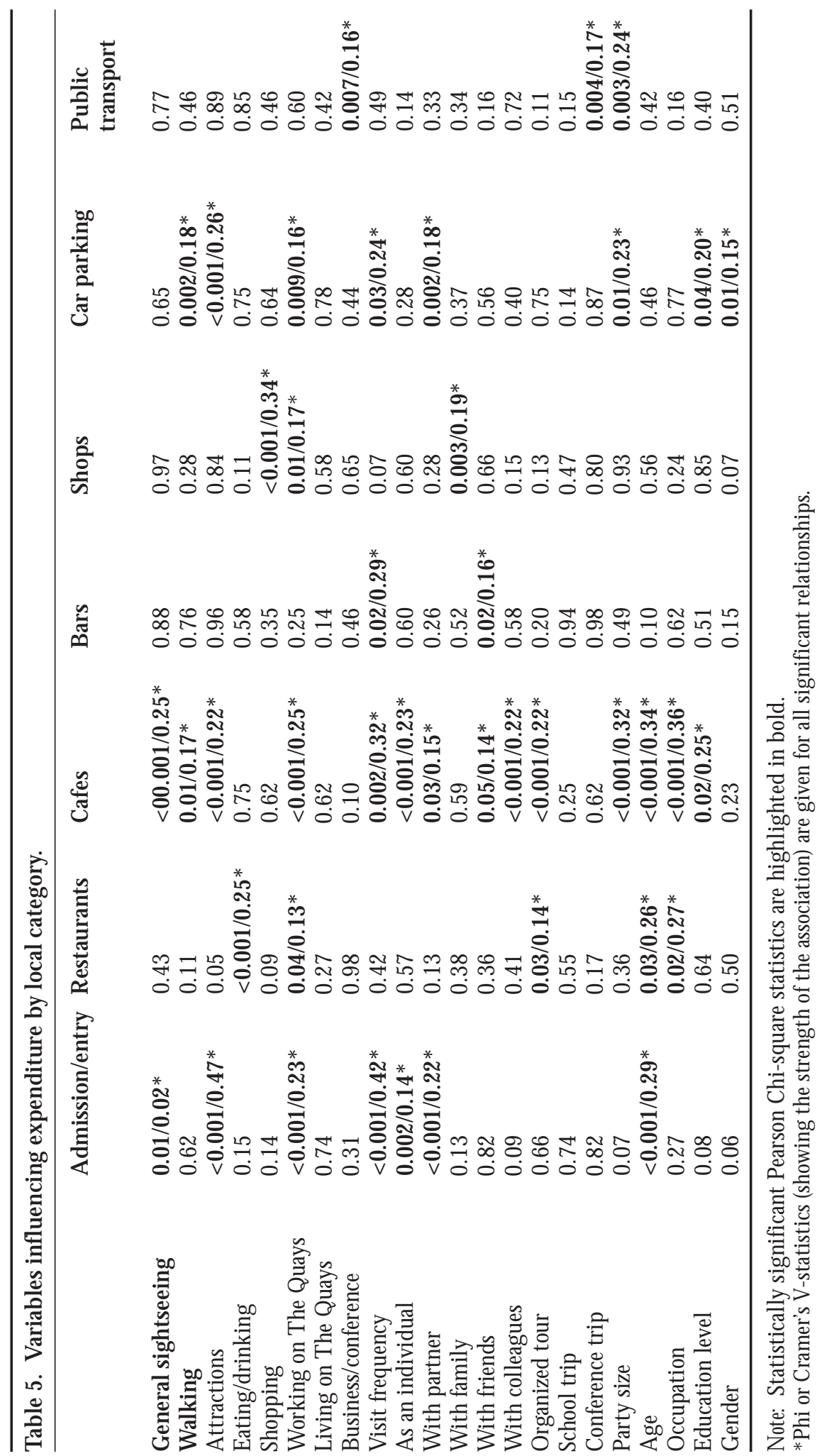


expenditure on shopping, visits with friends are associated with expenditure in cafes and bars, and visits with colleagues are associated with expenditure in cafes. Visitors' occupation and visitation on organized tours are associated with expenditure in restaurants and cafes. Visitor group size is associated significantly with expenditure in cafes and on car parking and public transport. H ighest level of education attained by visitors is associated significantly with expenditure in cafes and on car parking. There is also a significant association between gender and expenditure on car parking; female visitors tend to travel by car, perhaps for security reasons.

\section{Visitor expenditure profiles}

Statistically significant associations between the heavy, medium, light and no expenditure segments and a range of sociodemographic and behavioural variables were identified. There is a significant association between expenditure and gender (Table 6), with female visitors spending more than males. In a study of J apanese visitors to the USA, Jang et al (2004) found no significant gender influence, but the contextual differences between the two studies, that is, vacations in the case of the previous study and the day trip context here, may have influenced the different outcomes. Visitor age is also a significant influence on expenditure (Table 6). Young visitors (18-34) tend to be light or medium spenders compared with members of the older age groups (45-64), who tend to be medium to heavy spenders. By contrast, Mok and Iverson's (2000) study of Tai wanese visitors to Guam found heavy spenders to be significantly younger than medium or light segments. Again, differences in the product market context of the study may account for the discrepancy in outcomes.

Visit purpose is a significant influence on expenditure (Table 7). This generally supports the research of $\mathrm{MCH}$ one and Rungeling (1999), albeit on special cultural events. People who work for organizations located on The Quays tend to be in the light or no expenditure segments. General sightseers and people visiting attractions are predominantly medium spenders, visitors motivated primarily by eating and drinking tend to be medium and light spenders and shoppers tend to be heavy or medium spenders.

Group size is associated significantly with expenditure (Table 8); people who visit on their own tend to be light spenders and, in general, expenditure is associated positively with group size. This supports the findings of Spotts and Mahoney (1991), Agarnal and Yochum (2000) and Downward and Lumsdon (2003). Group characteristics are also a significant influence on expenditure (Table 8). People visiting al one tend to be light spenders compared with people visiting with partners or friends, who tend to be medium spenders. This supports the findings of D ownward and Lumsdon (2003) and J ang et al (2004). By comparison, family groups are medium to heavy spenders and people who visit The Quays with work colleagues tend to be light spenders or incur no expenditure. Table 8 also shows that visit frequency is a significant influence on expenditure. Visitors in the once-a-year category tend to be heavy to medium spenders compared with first-time visitors, who are medium to light spenders, and weekly visitors, who are light to medium spenders. This result lends some support to the findings of Gyte and Phelps (1989), rather than those of 
Table 6. Visitor gender, age and expenditure.

Heavy

$27(13.6 \%)$
$44(22.7 \%)$

Male

Female

A ge

18-24

$25-34$

$35-44$

$45-54$

$55-64$

$13(12.9 \%)$
$12(15.0 \%)$
$15(20.3 \%)$
$12(24.0 \%)$
$13(30.2 \%)$

\section{Expenditure segments}

Medium

Light

None

$32(16.2 \%)$

$24(12.4 \%)$
$74(37.4 \%)$

$56(28.9 \%)$

$$
\chi^{2}=7.85, d f=3, p=0.049
$$

\section{Expenditure segments}

Medium

$26(25.7 \%)$

$21(26.3 \%)$

$32(43.2 \%)$

$20(40.0 \%)$

$19(44.2 \%)$

Light

None

$x^{2}=33.44, d f=15, p=0.004$

Table 7. Visit purpose and expenditure.

\begin{tabular}{|c|c|c|c|c|}
\hline & & Expenditure segn & ments & \\
\hline & H eavy & Medium & Light & None \\
\hline W ork & $8(6.1 \%)$ & $\begin{aligned} & 20(15.2 \%) \\
\chi^{2}= & 78.97, d f=3, p<0.001\end{aligned}$ & $71(53.8 \%)$ & $33(25.0 \%)$ \\
\hline Sightseeing & $19(22.1 \%)$ & $\begin{aligned} & 43(50.0 \%) \\
\chi^{2}= & 17.6, d f=3, p<0.001\end{aligned}$ & $18(20.9 \%)$ & $6(6.9 \%)$ \\
\hline Walking & $8(22.9 \%)$ & $\begin{array}{c}16(45.7 \%) \\
\chi^{2}=4.87, d f=3, p=0.182\end{array}$ & $6(17.1 \%)$ & $5(14.3 \%)$ \\
\hline Attractions & $14(16.3 \%)$ & $\begin{aligned} & 49(56.9 \%) \\
\chi^{2}= & 26.96, d f=3, p<0.001\end{aligned}$ & $18(20.9 \%)$ & $5(5.8 \%)$ \\
\hline Eating/drinking & $26(20.8 \%)$ & $\begin{array}{c}52(41.6 \%) \\
\chi^{2}=11.67, d f=3, p=0.009\end{array}$ & $39(31.2 \%)$ & $8(6.4 \%)$ \\
\hline Shopping & $50(40.0 \%)$ & $\begin{array}{c}48(38.4 \%) \\
\chi^{2}=76.19, d f=3, p<0.001\end{array}$ & $16(12.8 \%)$ & $11(8.8 \%)$ \\
\hline
\end{tabular}

Oppermann (1997) and Jang et al (2004). It is interesting to note that Gyte and Phelps's (1989) research examined British tourists, albeit in a vacation context, in contrast to the other studies.

There is also a statistically significant relationship between expenditure and both overall satisfaction and likelihood of recommending The Quays to others (Table 9). Both have a positive association with expenditure. No significant associations were found between expenditure segments and visitor occupation $\left(\chi^{2}=29.20, \mathrm{df}=21, p=0.11\right)$, visitor origin $\left(\chi^{2}=18.42, \mathrm{df}=21, p=0.24\right)$ or likelihood of returning to The Quays $\left(\chi^{2}=12.34\right.$, df $\left.=12, p=0.42\right)$. 
Table 8. Group size, group composition, visit frequency and expenditure.

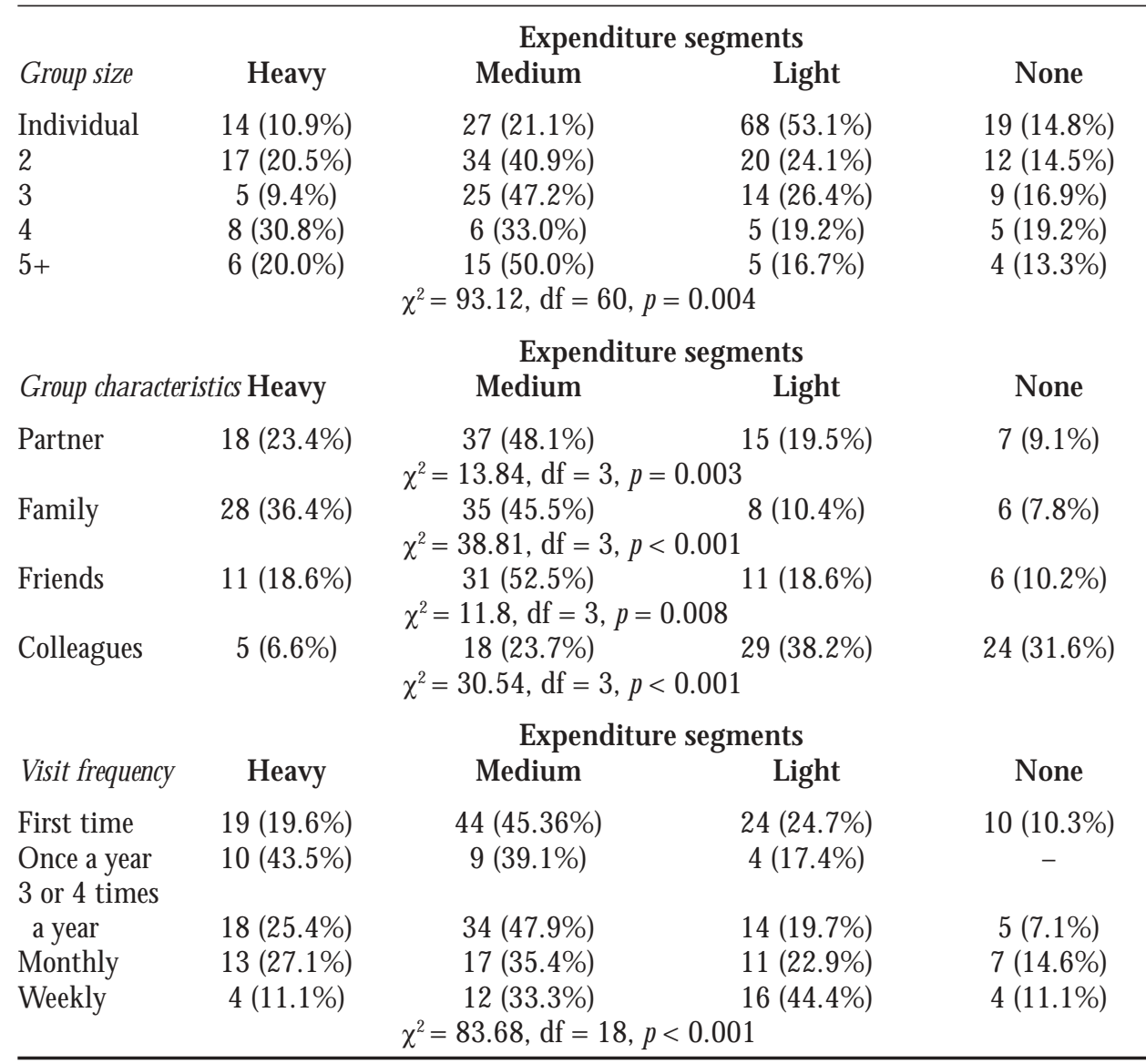

Table 9. Visitor satisfaction, recommendation and expenditure.

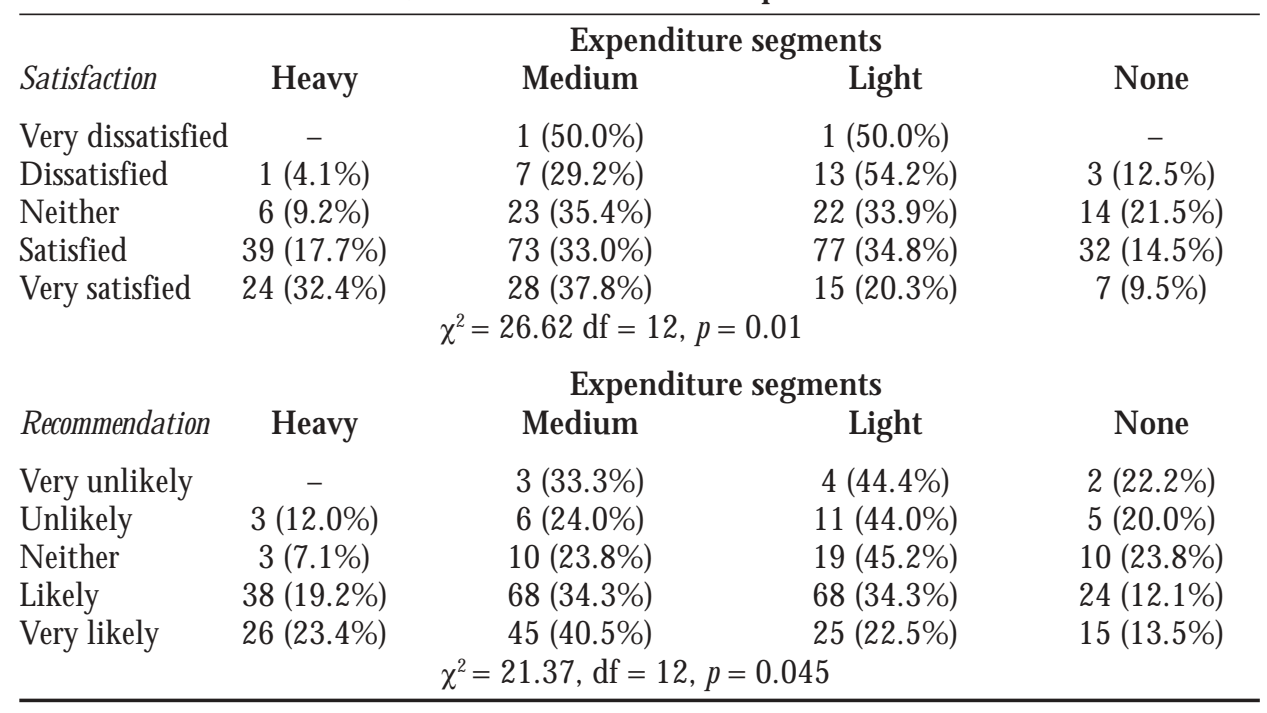


Overall, the significant associations suggest that the expenditure segments have the following general profiles. H eavy expenditure segment members are likely to be female, visiting with family and have shopping as the main motivation for the visit. Medium expenditure segment members are likely to be first-time visitors, visiting with a partner or family and motivated by attractions, eating and drinking and shopping. Light expenditure segment members are likely to be male, in the 18-24 age group, working on The Quays and eating or drinking either with colleagues or on their own.

\section{Conclusions}

The study examined day-trip visitor expenditure at The Quays in Salford, UK, by local expenditure category and heavy, medium, light and no expenditure segments. The data are considered to be rel iable because the problems associated with expenditure recall bias are minimal in comparison with studies that ask respondents to recall their expenditure over a longer period of time, notwithstanding the limitations imposed by the size and characteristics of the nonprobability sample. Statistically significant sociodemographic and trip-related influences were identified. Most visitor expenditure was on shopping and in restaurants and cafes, whereas expenditure on entry/admission to attractions and in bars was relatively low. Significant associations were found between expenditure in local categories and visitor age, gender, occupation, level of education, trip motivation, visitor type, group type, group size and visit frequency. Significant differences were also found between the expenditure of heavy, medium, light and no expenditure segments in all local categories. The heavy expenditure segment spent more than the light expenditure segment and either more than or equal to the medium expenditure segment in all local categories except cafes.

Age and gender were found to be significant influences on overall expenditure. By comparison, no significant differences in total expenditure were found on the basis of socio-economic class, level of education, business/conference attendance, organized tours, educational trips or visiting with partners, friends or colleagues. Total expenditure was significantly higher for shoppers than for non-shoppers, for leisure visitors than for subjects who work on The Quays and for infrequent visitors than for frequent visitors. Total expenditure was also significantly higher for persons visiting The Quays in groups. Overall, the proportion of variance in total expenditure explained by visitor age, frequency of visitation and shopping as the motivation for the visit were notably higher than for other significant variables.

Statistically significant associations between heavy, medium and light expenditure segments and gender, age, visit purpose, group size, group characteristics and visit frequency were identified. The significant influences on total and local category expenditure have important implications for overall planning and marketing of The Quays and that relating to the individual primary attractions and secondary facilities. Efforts to increase visitor expenditure at The Quays should focus on product augmentation and the design of promotional material to target more effectively the heavy expenditure segment, characterized by female visitors and family groups with shopping as 
the main motivation for the visit. The significantly higher ratings by the high expenditure segment on certain product attributes of The Quays suggest that targeted promotion should emphasize the new things to see and do, while featuring the destination as a place both for days out with the family and for good quality shopping.

The study makes a significant contribution to the academic literature because it focuses on micro-level visitor expenditure at a post-industrial urban waterfront tourism destination by examining patterns of expenditure by local category/tourism product component. Further, it identifies heavy, medium, light and no expenditure segments and examines the significance of a range of socio-economic and behavioural variables on visitor expenditure. The study also offers a methodological formula that could be applied to other regenerated urban waterfront destinations to assess visitor expenditure.

$M$ any of the findings from previous research relating to influences on visitor expenditure are supported by the results of this study. This may reflect general patterns and possibly universal influences, although the day trip context of this study compared with the international context of much of the previous research (and other contextual influences such as culture) suggests that further study is needed to assess the influence of different types of tourism destination and visitor. Further research is also needed both to distinguish heavy spenders from other segments more effectively and, in the case of The Quays, to establish the economic impact of local residents in comparison with business and leisure visitors. W ithout further research at different spatial scales, it is difficult to assess the contribution of the results to our overall understanding of destinationlevel expenditure and the variables that influence it. Clearly, further visitor expenditure research at the micro level is vital if we are to understand the economic potential of tourism-led urban regeneration and manage local tourism resources effectively in relation to visitor needs; the findings of this study suggest that this research should use actual rather than estimated expenditure data.

\section{References}

Agarnal, V.B., and Yochum, G.R. (2000), 'D eterminants of tourist spending', in Woodside, A.G., Crouch, G.I., Mazanec, J.A., O ppermann, M., and Sakai, M.Y., eds, C onsumer P sychol ogy of T ourism, $\mathrm{H}$ ospitality and Leisure, Volume 1, CAB International, Wallingford, pp 311-330.

Breen, H., Bull, B., and Walo, M. (2001), 'A comparison of survey methods to estimate visitor expenditure at a local event', Tourism M anagement, Vol 22, pp 473-479.

Davies, B., and Morgan, J. (1996), 'Family expenditure on hotels and holidays', A nnals of Tourism Research, Vol 19, N o 4, pp 691-699.

DeVaus, D.A. (2002), Surveys in Social Science Research, 5th Edition, Routledge, London.

Downward, P., and Lumsdon, L. (2000), 'The demand for day-visits: an analysis of visitor spending', Tourism Economics, Vol 6, No 3, pp 251-261.

Downward, P., and Lumsdon, L. (2003), 'Beyond the demand for day-visits: an analysis of visitor spending', Tourism Economics, Vol 9, No 1, pp 67-76.

Faulkner, B., and Raybould, M. (1995), 'Monitoring visitor expenditure associated with attendance at sporting events. An experimental assessment of the diary and recall methods', F estival M anagement and Event Tourism, Vol 3, No 2, pp 73-81.

Finn, M., Elliot-White, M., and Walton, M. (2000), Tourism and L es sure R esearch M ethods, Longman, London.

Frechtling, D.G. (1974), 'A model for estimating travel expenditures', J ournal of Travel Research, Vol 12 , N 0 4, pp 9-12. 
Godbey, G., and Graefe, A. (1991), 'Repeat tourism, play and monetary spending', A nnals of Tourism Research, Vol 18, N o 2, pp 213-225.

Gyte, D., and Phelps, A. (1989), 'Patterns of destination repeat business: British tourists in Mallorca, Spain', J ournal of Travel Research, Vol 28, No 1, pp 24-28.

J ang, S., Bai, B., H ong, G., and O'Leary, T.J . (2004), 'U nderstanding travel expenditure patterns: a study of J apanese pleasure travellers to the U nited States by income level', Tourism M anagement, Vol 25, No 3, pp 331-341.

J ennings, G. (2001), Tourism Research, Wiley, Milton, Queensland.

K rejcie, R.V., and Morgan, D.W. (1970), 'Determining sample size for research activities', Educational and Psychological Measurement, Vol 30, pp 607-610.

Legoherel, P. (1998), 'Toward a market segmentation of the tourism trade: expenditure levels and consumer behavior instability', Journal of Travel and Tourism M arketing, Vol 7, No 3, pp 19-39.

Lehto, X.Y., O'Leary, J.T., and M orrison, A.M. (2004), 'The effect of prior experience on vacation behavior', A nnals of Tourism Research, Vol 31, No 4, pp 801-818.

McH one, W.W., and Rungeling, B. (1999), 'Special cultural events: do they attract leisure tourists?', International Journal of $\mathrm{H}$ ospitality M anagement, Vol 18, pp 215-219.

M ok, C., and Iverson, T.J. (2000), 'Expenditure-based segmentation: Tai wanese tourists to Guam', Tourism M anagement, Vol 21, pp 299-305.

Oppermann, M. (1996), 'Visitation of tourism attractions and tourist expenditure patterns: repeat versus first-time visitors', A sia Pacific Journal of Tourism Research, Vol 1, No 1, pp 61-68.

Oppermann, M. (1997), 'First-time and repeat visitors to New Zealand', Tourism M anagement, Vol 18, pp 177-181.

Parlett, G., Fletcher, J., and Cooper, C. (1995), 'The impact of tourism on the old town of Edinburgh', Tourism M anagement, Vol 16, No 5, pp 355-360.

Pearce, D.C. (1988), 'Tourist time budgets', A nnals of Tourism R esearch, Vol 15, No 1, pp 106-121.

Petrick, J.F. (2005), 'Segmenting cruise passengers with price sensitivity', Tourism M anagement, Vol 26, N o 5, pp 753-762.

Pizam, A., and Reichel, A. (1979), 'Big spenders and little spenders in US tourism', J ournal of Travel Research, Vol 18, No 2, pp 42-43.

Salford City Council (2004), personal communication with Lindsey Hebden, Tourism and Marketing Manager, Salford City Council, Salford.

Sheldon, P.J. (1990), 'A review of tourism expenditure research', in Cooper, C.P., ed, Progress in Tourism, Recreation and H ospitality M anagement, Volume 2, Belhaven Press, London, pp 28-49.

Spotts, D.M., and Mahoney, E.M. (1991), 'Segmenting visitors to a destination region based on the volume of their expenditure', J ournal of Travel Research, Vol 29, No 4, pp 24-31.

Suh, Y.K., and M CAvoy, L. (2005), 'Preferences and trip expenditures - a conjoint analysis of visitors to Seoul, Korea', Tourism M anagement, Vol 26, N o 3, pp 325-333.

Vaughan, D.R., Farr, H., and Slee, R.W. (2000), 'Estimating and interpreting the local economic benefits of visitor spending: an explanation', L eisure Studies, Vol 19, pp 95-118.

Veal, A.J. (2006), R esearch M ethods for L eisure and Tourism, 3rd Edition, Pearson Education Limited, $\mathrm{H}$ arlow.

Walpole, M., and Goodwin, H. (2000), 'Local economic impacts of dragon tourism in Indonesia', A nnals of Tourism Research, Vol 27, No 3, pp 559-576.

W anhill, S. (1994), 'The measurement of tourism income multipliers', Tourism M anagement, Vol 15, No 4, pp 281-283.

Woodside, A.G., Cook, V.J ., and M indak, W. (1987), 'Profiling the heavy traveller segment', J ournal of Travel Research, Vol 25, No 3, pp 9-14. 